\title{
Radiological middle turbinate variations and their relation to nasal septum deviation in asymptomatic adult
}

\author{
Mohammad Waheed El-Anwar ${ }^{1}$, Atef Hamed Ali ${ }^{1}$, Rania Mostafa Almolla2*, Ghada Abdulmonaem², \\ Ashraf Raafat ${ }^{3}$ and Mohamed Elsayed Hassan ${ }^{4}$
}

\begin{abstract}
Background: Middle turbinate (MT) is one of the important anatomical and physiological structures of the nasal cavity. After the widespread use of nasal endoscope and paranasal sinus computed tomography (CT), many MT variations have been described. This study aimed to determine the incidence of MT variations by computed tomography (CT) in asymptomatic adult, their relation to each other, and to deviated septum (DS).

Results: In the included 86 subjects (172 MTs), pneumatized MT was the most common MT variation followed by paradoxical MT (PMT). Septal deviation did not appear to affect occurrence of pneumatized or PMT. Fifty-nine percent of the reported bilateral PMT were associated with pneumatized MT, while 35.7\% of unilateral PMT were associated with pneumatized MT with non-significant difference.
\end{abstract}

Conclusion: MT variations in adults are common mainly pneumatized MT then PMT with no apparent relation to septum deviation.

Keywords: Middle turbinate, Nose, Computed tomography, FESS

\section{Background}

Middle turbinate (MT) is one of the important anatomical and physiological structures of the nasal cavity. MT shares in regulation of airflow and temperature, airflow filtration, and olfaction [1]. After the widespread use of nasal endoscope and paranasal sinus computed tomography $(\mathrm{CT})$, many $\mathrm{MT}$ variations have been described such as paradoxically curved MT, pneumatized MT, secondary MT, and accessory and furcated MT [2]. The position and relationship of the MT to other important nasal structures is extremely important especially for pathogenesis of sinusitis, headache, and nasal obstruction, as well as, for endoscopic sinus and skull base surgery [3]. Concha bullosa (CB), the pneumatization of the concha, represents one of the most common sinonasal

\footnotetext{
*Correspondence: ranyaalmola@gmail.com

${ }^{2}$ Radiodiagnosis Department, Faculty of Medicine, Zagazig University, Zagazig, Egypt

Full list of author information is available at the end of the article
}

variations. Pneumatization of the concha is classified based on its location as bulbous $\mathrm{CB}$, lamellar $\mathrm{CB}$, and extensive CB [4]. A paradoxical MT (PMT) refers to an inferomedially curved MT edge with the concave surface facing the nasal septum [5]. PMT alone can lead to narrowing of the middle meatus up to obstruction of the ostiomeatal complex and interference with the physiological drainage of paranasal sinuses. In cases associated with bulbous MT, PMT potentially causes nasal obstruction [5]. The accessory MT is defined as a medially inclined uncinate process which may give the impression that two MTs are presented [6]. The secondary MT (SMT) is a bony structure in the middle meatus that originates from the lateral nasal wall. It is similar to the turbinate bone, and such variation is not related to osteomeatal obstruction and, therefore, it is not usually considered as a predisposing factor for sinusitis [7]. Furcated MT is a rare variant in which the turbinate splits into two (bifurcate) or three (trifurcate) divisions, giving 
Table 1 Incidence of middle turbinate variations

\begin{tabular}{|c|c|c|c|c|c|c|c|c|c|c|c|c|}
\hline & \multicolumn{9}{|c|}{ Pneumatized MT (88 sides 51.1\%) } & \multicolumn{3}{|c|}{ Paradoxical MT } \\
\hline & \multicolumn{3}{|c|}{ Bulbous concha } & \multicolumn{3}{|c|}{ Lamellar concha } & \multicolumn{3}{|c|}{ Total conchae } & & & \\
\hline & $46(20.9 \%)$ & & & $28(11.6$ & & & $14(8.1$ & & & $58(33.7 \%)$ & & \\
\hline & Right & Left & Bilateral & Right & Left & Bilateral & Right & Left & Bilateral & Right & Left & bilateral \\
\hline 86 subjects (172 sides) & $14(30.4 \%)$ & $12(26.1 \%)$ & $10(43.5 \%)$ & $8(29 \%)$ & $4(14 \%)$ & $8(57 \%)$ & 0 & 14 (100\%) & 0 & $10(17 \%)$ & $4(7 \%)$ & $22(76 \%)$ \\
\hline
\end{tabular}

the appearance of two or three MTs [8]. Study of these anatomical variations can assist in better understanding pathogenesis of infectious sinonasal diseases and increase the effectiveness and safety of endoscopic sinus surgery. This study aimed to determine the incidence of MT variations by $\mathrm{CT}$ in asymptomatic adult and their relation to each other and to deviated septum (DS).

\section{Methods}

This study was conducted in otorhinolaryngology and radiodiagnosis departments from July 2017 to January 2019. All participants were selected from subjects referred to CT examination of the head for different causes (brain, parotid gland, tempero-mandibular joint, and the mandible). CT examination of the nasal cavity was done as a part of the requested investigation, or additional selected cuts were applied after the first one.
Included subjects were asymptomatic adult (as regard nose and paranasal sinuses) without nasal pathology after proper history taking and clinical and CT examination. They were referred to as normal adult in the current study.

Informed written consent was signed by all subjected to contribute in the current study after explanation of our purposes. Subjects under the age of 16 years, patients with sinonasal disease, or patients who had previous sinonasal surgery or trauma were excluded from our study.

All CT examinations without using nasal decongestants were performed with a 64-multi-slice CT scan (Light speed volume VCT, GE medical system, Milwaukee, WI, USA). The protocol of MDCT was performed with a detector width $0.625 \mathrm{~mm}$, a section width $1.5 \mathrm{~mm}$, and $0.5 \mathrm{~mm}$ reconstruction interval.
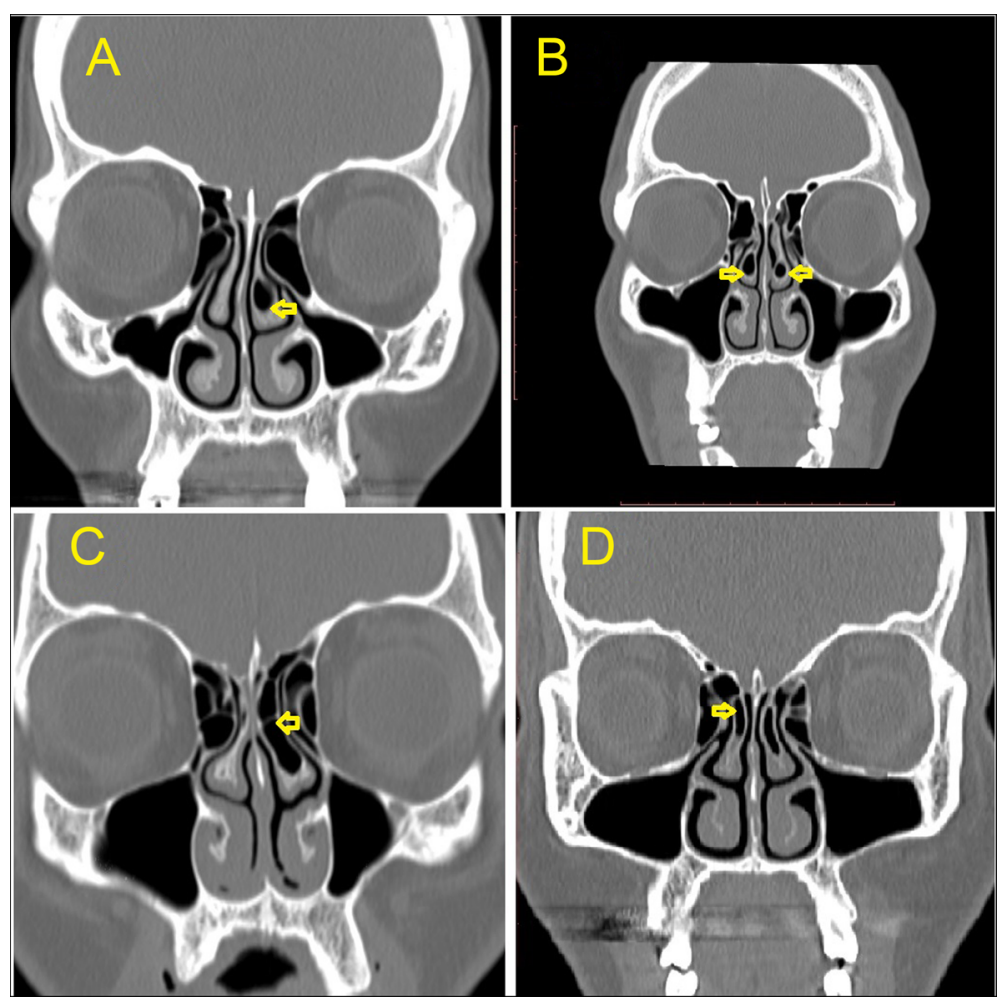

Fig. 1 Coronal CT scans of different pneumatized middle turbinate. a Left concha bullosa, b bilateral concha bullosa, c left total concha bullosa, d lamellar concha bullosa 
Table 2 Relation between septal deviation and MT variations

\begin{tabular}{|c|c|c|c|c|c|c|c|c|c|c|c|c|c|}
\hline \multicolumn{2}{|c|}{ Nasal septum } & \multirow{2}{*}{\multicolumn{3}{|c|}{$\frac{\text { Concha bullosa }}{46(20.9 \%)}$}} & \multirow{2}{*}{\multicolumn{3}{|c|}{$\frac{\text { Concha lamella }}{28(11.6 \%)}$}} & \multirow{2}{*}{\multicolumn{3}{|c|}{$\frac{\text { Total conchae }}{14(8.1 \%)}$}} & \multirow{2}{*}{\multicolumn{3}{|c|}{$\frac{\text { Paradoxical MT }}{58(20.9 \%)}$}} \\
\hline & & & & & & & & & & & & & \\
\hline \multirow{2}{*}{\multicolumn{2}{|c|}{$\begin{array}{l}\text { Central septum subjects } \\
\text { (sides) }\end{array}$}} & Right & Left & bilateral & Right & Left & Bilateral & Right & Left & Bilateral & Right & Left & bilateral \\
\hline & & $\begin{array}{l}11 \\
(38.9)\end{array}$ & $\begin{array}{l}5 \\
(33.3 \%)\end{array}$ & $\begin{array}{l}8 \\
(27.8 \%)\end{array}$ & $\begin{array}{l}5 \\
(40 \%)\end{array}$ & $\begin{array}{l}3 \\
(20 \%)\end{array}$ & $7(40 \%)$ & 0 & $\begin{array}{l}12 \\
(100 \%)\end{array}$ & 0 & $\begin{array}{l}8 \\
(27.8 \%)\end{array}$ & $\begin{array}{l}1 \\
(11 \%)\end{array}$ & $15(61 \%)$ \\
\hline \multirow{3}{*}{$\begin{array}{l}\text { Deviated } \\
\text { septum }\end{array}$} & Right & 1 & 3 & 1 & 2 & 0 & 1 & 0 & 1 & 0 & 0 & 1 & 5 \\
\hline & Left & 2 & 2 & 1 & 1 & 0 & 0 & 0 & 1 & 0 & 1 & 2 & 2 \\
\hline & Bilateral & 1 & 1 & 0 & 0 & 1 & 0 & 0 & 0 & 0 & 1 & 0 & 0 \\
\hline
\end{tabular}

MT middle turbinate

Axial images were performed while the subject was in supine position, and the beam was parallel to the subject hard palate. The cuts began from the hard palate to the top of the frontal sinus (glabella), using $130 \mathrm{kV}$ and 150 $\mathrm{mA} / \mathrm{s}$ and wide window (Window widths (WW) about 1300 to 2000 and window levels (WL) about - 80 to 200). High resolution algorithm was used for the enhancement of fine bony details.

Multiplanar reconstructions (MPR) with delicate details in the coronal and the sagittal planes for all subjects were post-processed at a dedicated workstation (Advantage Windows Volume share 4.5, GE Medical System, Milwaukee, WI, USA). Films were revised in the routine standardized fashion by one radiologist to confirm that small details were not missed. Each of the authors evaluated the CT cuts on all views in separate sessions and any discrepancy in evaluation was resolved and confirmed by the two radiologists.

Statistical analysis was performed using the SPSS statistical software package (version 18.0; SPSS, Inc., Chicago, IL, USA). $P$ value of less than 0.05 was considered statistically significant.

\section{Results}

Eighty-six Egyptian adult subjects (172 MTs) were included in the current study with a mean age of $31.7 \pm$ 10.5 (range 22-54), 54 females (63\%) and 32 male (37\%).

The reported variations of the MT are detailed in Table 1. Pneumatized MT was the most common MT variation detected and more than half of them were concha bullosa (51.1\%) while extensive (total) conchae were not detected bilaterally in any of our cases. PMT was the second most common detected variation that was found bilaterally in most cases (76\%) (Table 1) (Figs. 1 and 2).

Most concha bullosa and paradoxical MT were present with central septum. Concha was reported only in the same side of DS in 6 cases (3 concha bullosa, 2 lamella, 1 total), while concha was only documented in the contralateral side of DS in 6 cases (3 conchae bullosa, 2 lamella, 1 total). So DS did not appear to affect conchae (Table 2).

PMT was registered in the same side of the DS in 2 left sides and found in the contralateral side of the DS in two nasal sides (1 right and 1 left), so DS did not appear to affect PMT (Table 2).

Regarding relation of MT variations to each other, from the reported 22 bilateral PMT, 13 (59\%) of them were associated with pneumatized MT. While of the 14 unilateral PMT, 5 (35.7\%) were associated with pneumatized MT. But this difference was found non-significant $\left(X^{2}=1.87, p=0.171475\right)$ (Table 3).

\section{Discussion}

The advances in CT scanning and the wide spread of endoscopic sinus surgery increased the detection of MT variations. $M T$ variations include $C B$, PMT, and secondary and accessory MT. These variations and their relationship to DS may be a source of obstruction of the
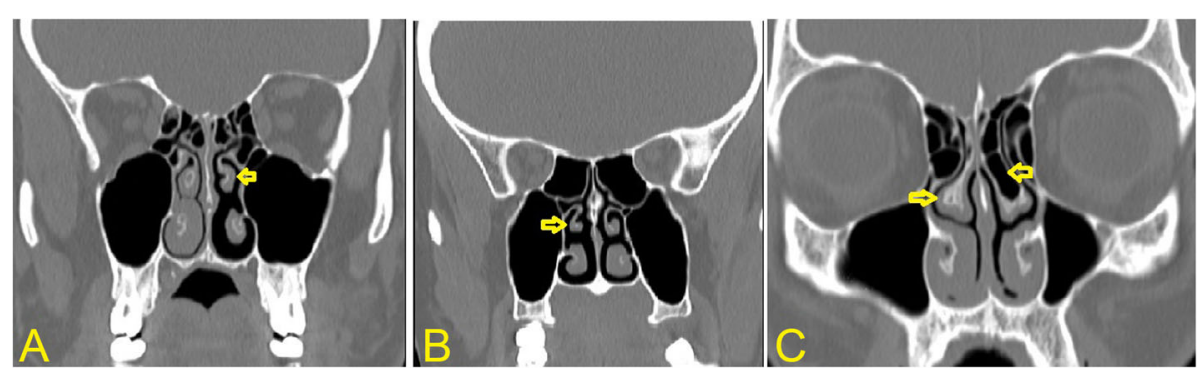

Fig. 2 Coronal CT different paradoxical middle turbinate (PMT). a Left PMT, b right PMT, c right PMT and left total concha bullosa 
middle meatal and subsequent headache and rhinosinusitis [9].

CT represents the gold standard diagnostic tool for the nasal and PNS pathologies, and multiple advanced techniques [10] are utilized now in pre-management of different nasal and PNS pathologies. Knowing detailed knowledge of the anatomical variants of the nasal turbinates is critical for effective and safe surgical procedures especially during functional endoscopic sinus surgery.

In current study, MT variations were studied using MSCT in asymptomatic adults with pathology-free nose and paranasal sinuses. The most frequent MT variation was concha bullosa (51.1\%), followed by PMT (33.7 \%), while the least frequent reported MT variation was bifid MT in one adult. The CB incidence was previously reported to range from 14 to $53 \%$ [11] and reaches up to $73 \%$ [12]. In current study, the incidence of frequency of types of CB was determined as $20.9 \%$ for bulbous concha, $11.6 \%$ for lamellar Concha, and $8.1 \%$ for total conchae. San et al. [11] have reported higher frequency of $\mathrm{CB}$ types such as $46.95 \%$ for total conchae, $32.17 \%$ for bulbous concha, and $20.86 \%$ for lamellar Concha. The differences could be attributed to racial difference and the analytical methods used. Frequencies of pneumatized MT and PMT in previous reports were $28 \%$ and $25 \%$ for Japanese [13], $24.5 \%$ and $10 \%$ in Spain [14], 29\% and $11 \%$ in Italian [15], $18.2 \%$ and $14.3 \%$ in Pakistani [16], and $31.1 \%$ and $7.5 \%$ in Nigerian subjects [17]. Environmental factors and genetics seem to be the attributed explanation for these variations.

In present study, prevalence of PMT was $33.7 \%$, and it was bilateral in $76 \%$ of the affected sides. Riello and Boasquevisque [12] and Fikre et al. [18] noted lower prevalence rate of $29 \%$ and $26.1 \%$, respectively.

Association of multiple MT anatomical variations was more with bilateral PMT and CB. Fifty-nine percent of the reported bilateral PMT was associated with pneumatized MT, while $35.7 \%$ of unilateral PMT were associated with pneumatized MT with non-significant difference. Some reports have suggested a relationship between the presence of a CB and DS, Tiwari et al. [19] found a strong relationship between the presence of a concha (a dominant or unilateral concha) and DS; in the other side, Vincent and Gendeh [20] disproved that DS is associated with $\mathrm{CB}$ in its development and pathogenesis of chronic rhinosinusitis.

Our study also showed no significant association between the most common MT anatomical variation as $\mathrm{CB}$ and PMT and the presence of ipsilateral or contralateral DS, so our study considered that CB and DS are coincidental variations.

The presence of these variations in our study in normal adult without rhinosinusitis may mean that no specific association of anatomic variations of MT and rhinosinusitis. This supports the hypothesis that local, systemic, environmental factors or intrinsic mucosal disease may be more significant in the pathogenesis of rhinosinusitis.

We used 64 MDCT, and application of such high multi-detector CT scanners or with higher detectors improve the image qualities [21,22]. The effective radiation dose used during sinus MDCT is $0.5-0.9 \mathrm{mSv}$ [23]. But, the familiarity with scanning parameters affecting the radiation dose and increased radiologists awareness are mandatory to achieve the highest image quality with the least exposure.

To the best of our knowledge, this is the first work describing the anatomical variations of the MT in Egyptian asymptomatic adult. Further studies are needed to compare such MT variation in different nasal pathologies and to compare between symptomatic and asymptomatic patients to assess the actual effect of these anatomical variants upon the clinical manifestation of the patients.

\section{Conclusion}

MT variations in adults are common mainly pneumatized MT then PMT with no apparent relation to septal deviation.

\section{Abbreviations \\ MT: Middle turbinate; DS: Deviated septum; PMT: Paradoxical MT; CB: Concha bullosa; SMT: Secondary middle turbinate; MPR: Multi-planner reconstruction; MSCT: Multislice computed tomography \\ Acknowledgements \\ Not applicable \\ Authors' contributions \\ All authors have read and approved the manuscript. Study concept and design was proposed by MWE and RA. Patient recruitment, follow-up, and acquisition of data by MWE, AA, and AR. Procedures were done by GA and}

Table 3 Multiple MT variations in the same subject

\begin{tabular}{|c|c|c|c|c|c|c|c|c|c|c|}
\hline \multirow[t]{2}{*}{ Variations } & \multirow[t]{2}{*}{ Number } & \multicolumn{3}{|c|}{ Concha bullosa } & \multicolumn{3}{|c|}{ Concha lamella } & \multicolumn{3}{|c|}{ Total conchae } \\
\hline & & Right & Left & Bilateral & Right & Left & Bilateral & Right & Left & bilateral \\
\hline Concha bullosa + bilateral paradoxical MT & 11subjects, 13 sides & 4 & 2 & 2 & 2 & & & & 1 & \\
\hline Concha bullosa + right paradoxical MT & 2 subjects, 3 sides & 1 (same) & 1 & & & & 1 (same) & & & \\
\hline Concha bullosa + left paradoxical MT & 2 subjects, 2 sides & 1 & & & & 1 & & & & \\
\hline
\end{tabular}


RA. Analysis and interpretation of data and drafting of the manuscript were done by MWE, $A A$, and $M H$. Revision of the manuscript; MWE, RA, and $A A$.

\section{Funding}

No funding was received for this research.

\section{Availability of data and materials}

The datasets used and/or analyzed during the current study are available from the corresponding author on reasonable request.

\section{Ethics approval and consent to participate}

All procedures performed in studies involving human participants were in accordance with the ethical standards of our institutional research committee of Zagazig University (No. not applicable) and with the 1964 Helsinki declaration and its later amendments or comparable ethical standards. Informed written consent was obtained from all individual participants included in the study.

\section{Consent for publication}

All patients included in this research gave written informed consent to publish the data contained within this study.

\section{Competing interests}

All authors declared that they had no competing interests.

\section{Author details}

'Otorhinolaryngology-Head and Neck Surgery Department, Faculty of Medicine, Zagazig University, Zagazig, Egypt. ${ }^{2}$ Radiodiagnosis Department, Faculty of Medicine, Zagazig University, Zagazig, Egypt. ${ }^{3}$ Otorhinolaryngology Department, Alahrar Teaching Hospital, Zagazig, Egypt.

${ }^{4}$ Otorhinolaryngology-Head and Neck Surgery Department, Faculty of Medicine, Banha University, Benha, Egypt.

Received: 11 May 2020 Accepted: 9 June 2020

Published online: 17 June 2020

\section{References}

1. Lee HY, Kim CH, Kim JY, Song MH, Yang HJ, Kim K et al (2006) Surgical anatomy of the middle turbinate. Clin Anat 19:493-496

2. Ozcan A, Selcuk A, Ozcan I, Akdogan O, Dere H (2008) Anatomical variations of nasal turbinates. J Craniofac Surg 19(6):1678-1682

3. Nicoleta M, Mugurel R, Mihal S (2008) Variant anatomy of nasal turbinates. Romanian J Morphol Embryol 56(3):1223-1226

4. Kalaiarasi R, Ramakrishnan V, Poyyamoli S (2018) Anatomical variations of the middle turbinate concha bullosa and its relationship with chronic sinusitis: a prospective radiologic study. Int Arch Otorhinolaryngol 22(3): 297-302

5. Măru N, Nc R, Săndulescu M (2015) Variant anatomy of nasal turbinates: supreme, superior and middle conchae bullosae, paradoxical superior and inferior turbinates, and middle accessory turbinate. Romanian J Morphol Embryol 56(3):1223-1226

6. Lin YL, Lin YS, Su WF, Wang CH (2006) A secondary middle turbinate coexisting with an accessory middle turbinate: an unusual combination of two anatomic variations. Acta Otolaryngol 126(4):429-431

7. El-Shazly AE, Poirrier AL, Cabay J, Lefebvre PP (2012) Anatomical variations of the lateral nasal wall: the secondary and accessory middle turbinates. Clin Anat 25:340-346

8. Rusu MC, Măru N, Sava CJ, Motoc A, Săndulescu M, Dincă D (2020) The sagittal grooves of the middle nasal turbinate determine paradoxical curvatures and bifidities. Niger J Clin Pract 23(4):464-469

9. Hatipoğlu HG, Cetin MA, Yüksel E (2005) Concha bullosa types: their relationship with sinusitis, ostiomeatal and frontal recess disease. Diagn Interv Radiol 11:145-149

10. Razek AA, Sieza S, Maha B (2009) Assessment of nasal and paranasal sinus masses by diffusion-weighted MR imaging. J Neuroradiol 36:206-211

11. San T, San S, Gürkan E, Erdoğan B (2014) Bilateral triple concha bullosa: a very rare anatomical variation of intranasal turbinates. Case Rep Otolaryngol 2014:851508

12. Riello APL, Boasquevisque EM (2008) Anatomical variants of the osteomeatal complex: tomographic findings in 200 patients. Radiol Bras 41(3):149-154
13. Tonai I, Baba S (1996) Anatomic variations of the bone in sinonasal CT. Acta Otolaryngol Suppl 525:9-13

14. Perez P, Sabate J, Carmona A, Catalina-Herrera CJ, Jimenez-Castellanos J (2000) Anatomical variations in the human paranasal sinus region studied by CT. J Anat 197:221-227

15. Mazza D, Bontempi E, Guerrisi A, Del Monte S, Cipolla G, Perrone A et al (2007) Paranasal sinuses anatomic variants: 64-slice CT evaluation. Minerva Stomatol 56:311-318

16. Adeel M, Rajput MS, Akhter S, Ikram M, Arain A, Khattak YJ (2013) Anatomical variations of nose and para-nasal sinuses; CT scan review. J Pak Med Assoc 63(3):317-319

17. Ameye S, Amusa Y, Eziyi J, Famurewa (2014) Assessing the surgical anatomy of the ethmoid sinus in adult Nigerian using CT. Int J Med Med Sci 6(12): 239-244

18. Fikret K, Onart S, Basut O (2009) Preoperative evaluation of chronic rhinosinusitis patients by conventional radiographics, computed tomography and nasal endoscopy. Kulak Burun Boğaz Ihtisas Dergisi 19(4): 184-191

19. Tiwari R, Goyal R (2019) Role of concha bullosa in chronic rhinosinusitis. Indian J Otolaryngol Head Neck Surg 71(1):128-131

20. Vincent T, Gendeh B (2010) The association of concha bullosa and deviated nasal septum with chronic rhinosinusitis in functional endoscopic sinus surgery patients. Med J Malaysia:108-111

21. Razek AA, Ezzat A, Azmy E, Tharwat N (2013) Role of whole-body 64-slice multidetector computed tomography in treatment planning for multiple myeloma. Radiol Med 118:799-805

22. Razek AA, Ghonim MR, Ashraf B (2015) Computed tomography staging of middle ear cholesteatoma. Pol J Radiol 80:328-333

23. Yamauchi-Kawaura C, Fujii K, Aoyama T, Yamauchi M, Koyama S (2009) Evaluation of radiation doses from MDCT-imaging in otolaryngology. Radiat Prot Dosim 136(1):38-44

\section{Publisher's Note}

Springer Nature remains neutral with regard to jurisdictional claims in published maps and institutional affiliations.

\section{Submit your manuscript to a SpringerOpen ${ }^{\circ}$ journal and benefit from:}

- Convenient online submission

- Rigorous peer review

- Open access: articles freely available online

- High visibility within the field

- Retaining the copyright to your article

Submit your next manuscript at $>$ springeropen.com 